\title{
SWINBURNE ON SUBSTANCE DUALISM
}

\section{LYNNE RUDDER BAKER}

\author{
University of Massachusetts Amherst
}

Richard Swinburne's Mind, Brain and Free Will is a tour de force. Beginning with basic ontology, Swinburne formulates careful definitions that support his mature philosophy. He is well-known for his views on free will and substance dualism. In Mind, Brain and Free Will, he revisits these issues among others, because he now has 'deeper and stronger' arguments for his position. Here I want to discuss substance dualism.

The first sentence of the book says that its focus is 'the nature of human beings - whether we are merely complicated machines or souls interacting with bodies' ${ }^{1}$ (Swinburne 2013: 1). Since I do not believe that this dichotomy is exhaustive, I shall first examine Swinburne's argument for the claim that human beings are 'souls interacting with bodies', which he interprets as substance dualism. Then, I shall offer a sketch of a different view - my own - which is materialistic in the sense that it makes reference neither to any immaterial concrete objects nor to any immaterial properties (whatever that might mean). I do not say that my materialistic view is a complete metaphysics, inasmuch as that it pertains only to the natural world. I leave it open whether there is a supernatural world.

Since I am going to offer an alternative to Swinburne's substance dualism, let me begin by enumerating ways in which I am in full agreement with him. I fully agree with Swinburne that it is not the case that 'mental events are merely brain events', and it is not the case that 'I am the same thing as my body' (Baker 1995; Baker 2000). With Swinburne,

\footnotetext{
${ }^{1}$ Since Swinburne begins with a dichotomy between human beings' being machines or souls, and goes on to argue that we are mental substances, I assume that he takes mental substances to be souls (i.e., immaterial substances).
} 
I reject a Humean theory of causation in favour of a causal-powers view (Baker 2007a). And I thoroughly agree with Swinburne's rejection of the principle of the causal closure of the physical (Swinburne 2013: 104-123; cf. Baker 2009). Moreover, I also have a 'simple view' of personal identity (Baker 2012). ${ }^{2}$ Now to turn to Swinburne.

In Chapter One, Swinburne takes considerable pains to set out his ontology. The history of the world is 'all the events that have occurred, are occurring, or will occur' (Swinburne 2013: 9). Events have as constituents substances, properties and times. So, the categories needed to tell the whole history of the world - the data of mental and physical life - are substance, property and time. Since Swinburne says that 'we can cut up the world into substances in different arbitrary ways and still tell the same world story' (Swinburne 2013: 38), we need a way to determine when 'two referring descriptions pick out the same property, substance or whatever'. Two referring descriptions pick out the same property (or whatever) if and only if that property 'can be designated by the same informative designator' (Swinburne 2013: 10). Swinburne's dualism rests on his claim that mental properties and physical properties cannot be picked out by the same informative designator. (Swinburne 2013: 69)

\section{INFORMATIVE DESIGNATORS}

Since Swinburne's notion of informative designators carries a lot of weight, we face the question of what an informative designator is. Swinburne says:

For a rigid designator of a thing to be an informative designator it must be the case that anyone who knows what the word means (that is has the linguistic knowledge of how to use it) knows a certain set of conditions necessary and sufficient (in any possible world) for a thing to be that thing (whether or not he can state those conditions in words). ${ }^{3}$ (Swinburne 2013: 12; my emphasis)

${ }^{2}$ However, since I believe in ontological vagueness, I disagree with Swinburne's account of the history of the world that holds that 'each substance com[es] into existence at a certain instant', which in 'the precise mathematical sense of the word [is] not temporally extended' (Swinburne 2013: 8). This is all the more surprising since he also says, 'All events take time.' (Swinburne 2013: 148)

${ }^{3}$ I assume that the informative-/uninformative-designator distinction applies only to rigid designators. 
He elaborates: 'Two informative designators are logically equivalent if and only if they are associated with logically equivalent sets of necessary and sufficient conditions.' (Swinburne 2013: 12) And mental properties are not identical to physical properties because their informative designators are not logically equivalent. (Swinburne 2013: 68)

Swinburne gives some examples: 'Red' is an informative designator, he says, because anyone who knows what the word means can apply it correctly if she is favourably positioned with faculties in working order and not subject to illusion. By contrast - another example of Swinburne's - 'water' (as used in the $18^{\text {th }}$ century) was an uninformative designator of the property of being $\mathrm{H}_{2} \mathrm{O}$ because 'however favourably positioned you are and however well your faculties are working you may not be able to identify correctly some liquid not in our rivers and seas as water' (Swinburne 2013: 12). However, as used today, 'water' is an informative designator. Swinburne comments: 'Whether or not a word is an informative designator is a matter of the rules for its current use in the language.' (Swinburne 2013: 14)

The distinction between informative and uninformative designators is important for Swinburne, not only because it is used to individuate properties, but also it figures in a restriction on telling the whole story of the world: We must specify the events that make up the history of the world in terms of properties and substances picked out by informative designators. Because 'such designators will pick out the same properties and so on [if and only if] they are logically equivalent', this restriction enables us 'to tell the whole history of the world ... by listing a subset of events which entails all events' (Swinburne 2013: 23).

Let us now turn to some potential problems with Swinburne's characterization of an informative designator in terms of a speaker's knowledge of a set of necessary and sufficient conditions for its application.

First, Swinburne says, "My knowledge of how to use "I" ... means that I know the nature of what I am talking about when I use the word.' (Swinburne 2013: 158) Later, Swinburne argues that it is the nature of a human person to be a mental (immaterial) substance. And what's true for me about my use of 'I' is true for everyone who uses 'I'. (Swinburne 2013: 158) Surely, if one's knowledge of how to use 'I' meant that one knew 'the nature of what [one is] talking about', then on Swinburne's view, everyone who used 'I', should know that she was a mental substance. But 
that is clearly wrong. I (LB) can use 'I' competently, but I do not believe that I am a mental (i.e., immaterial - see note 1) subject.

Second, I have the linguistic knowledge of how to use 'arthritis', but I do not know 'a certain set of necessary and sufficient conditions (in any possible world) for a thing to be' arthritis - even though I know that arthritis is some painful condition of the joints. I don't even know any necessary and sufficient conditions for a thing to be red (Swinburne's example of an informative designator). Is a reddish-orange poppy red? Is a reddish-yellow bruise red? Of the words that I use competently, there are not many (if any) for which I know any necessary and sufficient conditions. (cf. Merricks 1998)

Third, Swinburne's characterization of informative designators not only leaves indeterminacies that are relative to 'the rules for its current use in language', as in the case of 'red'; but his characterization also relativizes an informative designator to a speaker's current knowledge. A young child can competently use 'water' (in its current usage) without knowing that water is $\mathrm{H}_{2} \mathrm{O}$; so in the child's mouth, 'water' is an uninformative designator; but in the mouth of her mother, who knows that water is $\mathrm{H}_{2} \mathrm{O}$, 'water' is an informative designator. It follows that, on Swinburne's characterization, a single term can be used competently by two people at the same time in the same linguistic community, and in one case it is an uninformative designator and in the other case it is an informative designator. The relativity of a word's being an informative designator, not only to time but also to speaker, seems to vitiate the usefulness of informative designators for telling the whole story of the world.

Swinburne does say that an informative designator is such that anyone who 'has the linguistic knowledge of how to use it' knows a certain set of conditions necessary and sufficient for its application, 'whether or not he can state those conditions in words' (Swinburne 2013: 12). In all of my examples - e.g., 'red', 'I', 'arthritis' - the speaker has the linguistic knowledge of how to use a term without knowing, even in some implicit way, any necessary and sufficient conditions for the term's application.

In sum, if neither 'red', nor ' $\mathrm{I}$ ', nor 'arthritis' is an informative designator, and if 'water"s being an informative designator is relative, not only to time, but also to speaker, it is difficult to see that there are any informative designators - certainly not enough to tell the whole story of the world - on Swinburne's characterization. Hence, Swinburne's notion of an informative designator does not seem up to the task of picking out all the properties needed to tell the history of the world. 


\section{IDENTITY CRITERIA FOR COMPOSITE SUBSTANCES}

Swinburne has a principle of identity for composites. (Composites are substances with parts - like human organisms and artefacts.) One way to express his principle is that 'there is no more to any substance than its parts (e.g., fundamental particles) and the way those parts are arranged' (Swinburne 2013: 35). Swinburne says that our normal criteria for the identity of a ship over time in terms of parts are too vague to resolve the 'ship of Theseus' puzzle. We can make them more precise, Swinburne says, in either of two ways: the continuity of planks arranged in a certain way determines the identity of the ship; or the identity of the planks determines the identity of the ship. 'We can tell the story either way without anything being omitted.' (Swinburne 2013: 31)

Can this claim about the ship of Theseus really be true, on Swinburne's view? It may make a difference in the history of the world which ship is the original ship after the change of planks - the ship with reassembled old planks or the ship with the new planks. To see this, suppose that, although the original ship was owned by Theseus, the replacement planks were owned by Minos. If we said that the continuously-existing ship was the ship of Theseus, then Theseus would own a ship all of whose planks were owned by Minos. If the original ship of Theseus had been insured, then there would be a difference in which resulting ship ended up insured. If an insurance claim were filed, which ship was identical to the ship of Theseus would make a difference in the history of the world. So, we couldn't tell the story 'either way without anything being omitted'.

Swinburne holds that we can tell the history of the world with stories in terms of fundamental particles, and also with stories in terms of 'organisms and artefacts' (and, I assume, mental substances). (Swinburne 2013: 32) However, if substances are no more than their parts in certain arrangements, it seems to follow that artefacts cannot be substances. The exclusion of artefacts as substances so construed can be illustrated by a fanciful example of two (non-identical) kinds of artefacts made of duplicate qualitatively identical parts arranged in the same way: Suppose that someone invented a device that mixed water and air and was used in a process of making soft drinks; call the device a 'drinkalator'. Suppose that it turned out that exactly the same physically possible structures that could be drinkalators could also be carburettors. But drinkalators are not identical to carburettors, which mix gasoline and air in automobiles; both types of artefacts are distinguished by the intentions and practices of the 
designers, manufacturers, and users. The identity of an artefact is not determined by its parts and their arrangement: ' $\mathrm{X}$ is a carburettor' and ' $\mathrm{X}$ is a drinkalator' have different truth conditions. (Baker 1995: 195-99) No carburettor is identical to a drinkalator. So, either carburettors and drinkalators - and artefacts generally - fail to be substances or Swinburne's principle of the identity of composites is incorrect.

Other terminological matters: Swinburne defines a mental property 'as one to whose instantiation in it a substance necessarily has privileged access on all occasions of its instantiation' (Swinburne 2013: 67). And 'A mental substance is one for which the possession of some mental property is essential' (Swinburne 2013: 43). A physical property is defined 'as one to whose instantiation in it a substance necessarily has no privileged access on any occasion of its instantiation' (Swinburne 2013: 68). A pure mental property is defined as one 'whose instantiation in a substance does not entail the instantiation of any metaphysically contingent physical property in that substance' (Swinburne 2013: 68).

I shall construe the definition of a mental property to be logically equivalent to this (which seems to me slightly easier to understand): A mental property is one to whose instantiations a substance that instantiates it has privileged access - i.e., substances have privileged access to the mental properties that they instantiate.

\section{SWINBURNE'S ARGUMENTS FOR SUBSTANCE DUALISM}

I am not confident that I understand Swinburne's argument for mental substances from synchronic unity, but if I do, it goes like this: ${ }^{4}$

(1) A complete history of the world must include 'among substances with physical properties and so physical parts, substances which are such that events in those parts are the immediate causes or effects of and only of conscious events which are coexperienced with other conscious events belonging to the same substance' (Swinburne 2013: 143).

(2) The property of coexperiencing certain properties at a time 'will delimit the physical boundaries of the substance, and so help to determine which physical properties it possesses' (Swinburne 2013: 143).

${ }^{4}$ Swinburne 2013: 43. This is Swinburne's argument from the synchronic unity of a person. If the argument is sound, it establishes substance dualism. 
(3) The property of coexperiencing certain properties at a time is a mental property. [Defn. of mental property plus the fact that one has privileged access to instantiations of coexperiencing.]

(4) If (2) and (3), then 'a substance which has conscious coexperienced properties is ... determined in part by a mental property' (Swinburne 2013: 143).

(5) If a substance which has conscious coexperienced properties is ... determined in part by a mental property, then that substance is a mental substance. [alternative definition of mental property]

(6) Humans 'are mental substances, since their spatial boundaries are determined by a mental property' (Swinburne 2013: 144).

I have a worry about (2), and consequently about (5) and (6). First (2): I wonder if 'delimit' is used equivocally. (2) may be true if 'delimit' is a causal idea, as in interactive dualism; but in order to support (5), Swinburne needs a stronger ontological reading of (4). Determination is an ontological idea, not merely a causal one. If coexperiencing certain properties at a time will 'help to determine which physical properties it possesses', then the connection between the coexperiencing and the physical properties that the coexperiencing helps to determine must be stronger than merely causal.

To put it another way, (2) is true only if 'delimit' is understood causally; but if 'delimit' is understood causally, then (2) does not support the conclusion (6). So, either the argument has a false premise or is invalid. Either way, it is unsound.

Does Swinburne's argument from diachronic unity of a person fare any better? What follows is my best idea of how the argument goes (again, I am uncertain):

(1) My use of the word 'I' is as an informative designator. (Swinburne 2013: 158)

(2) If (1), then 'I know the nature of what I am talking about when I use the word' 'I'. (Swinburne 2013: 158)

(3) What's true for me about my use of 'I' is true for everyone who uses 'I'. (Swinburne 2013: 158)

(4) If (2) and (3), then '[e]ach of us ... can continue to exist without any continuity of brain, memory or character'. (i.e., The 'simple theory of personal identity is correct'.) (Swinburne 2013: 158)

(5) If each of us ... can continue to exist without any continuity of brain, memory or character, then each of us is a 'particular subject 
of experiences (that is, of conscious events), and so a mental substance who exists over time' (Swinburne 2013: 159).

(6) Each of us is a 'particular subject of experiences (that is, of conscious events)'.

(7) If (6), then each of us is a 'particular mental substance who exists over time.' [Swinburne 2013, 159-60]

(8) Each of us is a 'particular mental substance who exists over time' (Swinburne 2013: 160).

The main problem with this argument, I think, is that the truth of (7) requires that subjects of experience are mental (immaterial) substances - the conclusion of the argument from synchronic identity, which we found to be unsound. (I criticized premise (1) in the section on Informative Designators.)

To sum up, there seem to be difficulties with the application of informative designators to the individuation of properties, with the application of Swinburne's criteria of identity for substances to the shipof-Theseus case, and with his principle of the identity of composites. Moreover, neither the argument from synchronic unity nor the argument from diachronic unity for substance dualism seems sound. In light of these at least provisional problems, it seems that a view of persons that does not countenance mental substances, but satisfies first-personal desiderata for persons should be a contender.

\section{A CONSTITUTION VIEW OF PERSONS}

Since I intend this discussion to focus on Swinburne, I shall sketch my alternative only briefly.

On my view a person has a first-person perspective essentially, and a human person is embodied essentially, although she does not necessarily have the body she has now. The first-person perspective is a dispositional property that has two stages: a rudimentary stage that human infants share with higher nonhuman animals, and a robust stage that human persons develop as they learn a language. (For details see Baker 2013.)

The relation between a person and her body is constitution. Every concrete object that exists is of some primary kind or other, and has its primary-kind property essentially. Person is a primary kind; teacher is not. Constitution is a contingent relation of unity between things of 
different primary kinds. Human persons begin existence constituted by human organisms that support first-person perspectives. (Later, with enough bionic replacements, a human person may come to have a nonorganic body, but the person is always embodied as long as she exists.) The unity of persons, and of much else, is provided by constitution and the first-person perspective. (For details, see Baker 2007b; Baker 2007a; Baker 2013)

Persons are of different primary kinds from bodies, human or otherwise. (Persons have first-person persistence conditions; bodies do not. Persons have innumerable causal powers that bodies lack.) Nevertheless, my view is not a property dualism. On my view, there are not two kinds of properties; there are myriads of kinds of properties, none of which is instantiable only by immaterial substances. (I do not believe that there are any finite immaterial substances.)

My view is nonreductive throughout. I am as nonreductive about artefacts as I am about natural objects: 'Every thing is what it is and not another thing', and that goes for the familiar things that we interact with. ${ }^{5}$ Being a dialysis machine is as irreducible (and hence as much are part of basic ontology) as being a person or being a human organism.

Hence, the relevant charge against me is not property dualism; a better criticism is that my ontology includes too many concrete objects and properties, that my ontology is bloated. I accept the charge as the price for being nonreductive. So, I am no dualist; I don't stop at two kinds of substances or properties.

One advantage of the Constitution View over Substance Dualism is that there is not (or rather I cannot think of) any naturalistic way that an immaterial mind could have come into existence, but I can think of a naturalistic way that the first-person perspective could have come into existence: the rudimentary stage of the first-person perspective consciousness and intentionality - seems to have evolved gradually over many species (from the first stirrings of intentionality in organisms with limited flexibility in responding to their environments to the more developed intentionality of mammals); ${ }^{6}$ and the robust stage comes into existence as human beings developed syntactically complex languages with resources for first-person reference and attribution of first-person

${ }^{5}$ The quotation is attributed to Joseph Butler.

${ }^{6}$ I think that there is no doubt that dogs behave intentionally and are conscious, Descartes notwithstanding. 
reference. There are thus nonmagical explanations for both stages of the first-person perspective.

Finally, I reject any claim (like Swinburne's) that objects should be understood in terms of their parts. The identity and arrangement of parts do not always (or even usually) determine the identity of wholes. Artefacts and artworks are ontologically intention-dependent; in the absence of intentions (of designers, manufacturers, users, artists), there could be no artefacts or artworks. Even if indiscernible duplicates of, say, dialysis machines spontaneously coalesced in outer space, such objects would not be dialysis machines. Dialysis machines are the things they are because they have the intended function to replace lost kidney-function artificially; machines with such intended functions could not exist in the absence of laboratories and medical practices. When we focus on parts and their arrangement, what is essential becomes invisible.

Despite my differences with Swinburne, I believe that he and I share certain desiderata in our theories about human persons:

(a) A human person is not identical to her body at any time.

(b) A human person can survive a complete change of body.

(c) Not all truths about persons are truths about bodies.

(d) The property of being a person entails the instantiation of mental properties - at least a rudimentary first-person perspective.

(e) The persistence of persons is primitive (as the Simple Theory of Personal Identity over time implies).

\section{CONCLUSION}

Mind, Brain and Free Will is a closely argued comprehensive work on major themes of Swinburne's. I have discussed only a few aspects of Swinburne's views bearing on substance dualism. In the belief that we can (and should) reject the dichotomy that Swinburne began his book with - that human beings are either 'merely complicated machines or souls interacting with bodies' - I offered an alternative that I believe achieves much of what substance dualists want. 


\section{REFERENCES}

Baker, Lynne Rudder. 1995. Explaining Attitudes: A Practical Approach to the Mind (Cambridge: Cambridge University Press)

- 2000. Persons and Bodies: A Constitution View (Cambridge: Cambridge University Press)

- 2007a. 'Naturalism and the First-Person Perspective', in How Successful Is Naturalism?, ed. Georg Gasser, (Frankfurt: Ontos-Verlag) pp. 203-227

- 2007b. 'Persons and the Metaphysics of Resurrection', Religious Studies, 43 (3): $333-348$

- 2009. 'Nonreductive Materialism', in The Oxford Handbook of Philosophy of Mind, ed. Brian P. McLaughlin, Ansgar Beckermann, and Sven Walter (Oxford: Clarendon Press), pp. 109-127

- 2012. 'Personal Identity: A Not-So-Simple Simple View', in Personal Identity: Complex or Simple?, ed. Matthias Stephan and Georg Gasser (Cambridge: Cambridge University Press), pp. 179-191

- 2013. Naturalism and the First-Person Perspective (New York: Oxford University Press)

Merricks, Trenton. 1998. 'There Are No Criteria of Identity over Time', Nous, 32 (1): 106-124

Perry, John. 2002. 'The Sense of Identity', in Identity, Personal Identity, and the Self (Indianpolis, IN: Hackett Publishing Company, Inc.), pp. 214-243

Swinburne, Richard. 2013. Mind, Brain and Free Will (Oxford: Oxford University Press) 